$$
\text { http://dx.doi.org/10.12819/2022.19.2.1 }
$$

\title{
OSS: Uma Investigação Sobre a Dissonância Entre o Mainstream Expectativa-Desempenho e a Satisfação entre Praticantes de Jiu-Jitsu À Luz do Marketing Experiencial
}

\section{OSS: An Investigation About Dissonance Between Expectation-Performance Mainstream and Satisfaction Among Jiu-Jitsu Practitioners Under the Aegis of the Experiential Marketing}

Renato Borges Fernandes

Doutorado pela Universidade Federal de Lavras Mestre em Administração pela Faculdade de Estudos Administrativos de Minas Gerais Professor e Pró-Reitor de Planejamento, Administração e Finanças pelo UNIPAM E-mail: renato@unipam.edu.br

\section{Custódio Genésio da Costa Filho}

Doutor em Administração pela Universidade Federal de Lavras Professor da Universidade Federal de Viçosa - Campus Florestal E-mail: custodio@ufv.br

Ronaldo Pereira Caixeta

Mestre em Administração de Empresas pela Faculdade de Estudos Administrativos de Minas Gerais Professor Assistente e Coordenador da Comissão Própria de Avaliação do UNIPAM

E-mail: ronaldo@unipam.edu.br

Daniel Carvalho de Rezende

Doutor em Desenvolvimento, Agricultura e Sociedade pela Universidade Federal Rural do Rio de Janeiro Professor Adjunto e Coordenador do Programa de Pós-Graduação em Administração

E-mail: danielderezende@ufla.br

Endereço: Renato Borges Fernandes Rua Major Gote, 808, CEP: 38702-054, Caiçaras, Patos de Minas, MG. Brasil.

Endereço: Custódio Genésio da Costa Filho Rodovia LMG 818, Km 06, s/n, Campus Universitário, CEP: 35690-000 Florestal, MG. Brasil.

Endereço: Ronaldo Pereira Caixeta

Rua Major Gote, 808, CEP: 38702-054, Caiçaras, Patos de Minas, MG. Brasil.

Endereço: Daniel Carvalho de Rezende Aquenta Sol - DAE, Bloco III, Campus Universitário, CEP: 37200-900, Lavras, MG. Brasil.
Editor-Chefe: Dr. Tonny Kerley de Alencar Rodrigues

Artigo recebido em 25/08/2021. Última versão recebida em 02/09/2021. Aprovado em 03/09/2021.

Avaliado pelo sistema Triple Review: a) Desk Review pelo Editor-Chefe; e b) Double Blind Review (avaliação cega por dois avaliadores da área).

Revisão: Gramatical, Normativa e de Formatação 


\section{RESUMO}

A prática de jiu-jitsu traz diversos benefícios para quem o pratica, mas, principalmente para atletas em treinamento para campeonatos, pode ser extremamente desgastante. Contudo, ao final, esses benefícios trazem sentimento de satisfação que se distancia do processo para alcançá-lo. Assim, questiona-se: como serviços que demandam exigências negativas podem gerar satisfação? Destarte, o objetivo desse estudo foi comparar a perspectiva mainstream de análise de satisfação do cliente em serviços, baseada na relação expectativa-resultados, com a perspectiva de marketing de experiências, utilizando-se da prática de jiu-jitsu para campeonatos. $\mathrm{O}$ arcabouço teórico ancora-se em comparativo entre o mainstream expectativadesempenho-satisfação, em que a satisfação geral sobre serviços é dada pela diferença entre o esperado e o realizado, e o marketing experiencial, em que emoções e incertezas do indivíduo interferem nesta relação. Os resultados demonstram atributos considerados como negativos durante o processo de treinamento e incertezas quanto aos seus resultados e desempenho no campeonato. Contudo, estes atributos foram suplantados, gradativamente, levando à satisfação durante o processo e à satisfação final positiva. Pôde-se inferir que houve dissonância no paradigma expectativa-desempenho-satisfação, corroborando com a literatura sobre marketing experiencial de que em serviços que haja incertezas e fortes emoções envolvidas, a satisfação geral é função muito mais da superação e conquista do que com a relação expectativa e desempenho. Como é um trabalho exploratório, demanda-se estudo mais aprofundado, com mais casos e abordando quais aspectos das emoções e incertezas direcionam a dissonância observada.

Palavras-chave: Marketing Experiencial. Expectativa-Desempenho. Satisfação. Mainstream. Jiu-jitsu.

\section{ABSTRACT}

The jiu-jitsu practice brings several benefits to those who practice but especially for athletes in training for championships can be extremely exhausting. However, in the end, they bring a feeling of satisfaction that distances itself from the process to achieve it. Thus, the following question is asked: how can services that demand negative requirements generate satisfaction? Thus, the objective of this study was to compare the mainstream perspective of customer satisfaction analysis in services, based on the expectation-results relationship, with the perspective of marketing of experiences, using jiu-jitsu practice. The theoretical framework based itself on comparison between the mainstream expectation-performance-satisfaction, which the general satisfaction over services is given by the difference between that was expected and realized, and the experiential marketing, in which emotions and uncertainties of the individual interfere in this relation. The results demonstrate attributes considered negative during the training process and uncertainties regarding their results and performance in the championship. However, these attributes were gradually supplanted, leading to satisfaction during the process and positive final satisfaction. It is concluded that there is a rupture in the expectation-performance-satisfaction paradigm, corroborating with the literature on experiential marketing that in services that have uncertainties and strong emotions involved, general satisfaction is a much more function of overcoming and conquering than with the relation expectation performance. As it is an exploratory research, further study is required with more cases and addressing which emotional aspects and uncertainties drive the observed dissonance.

Keyword: Experiential Marketing. Expectancy-Performance. Satisfaction. Mainstream. Jiujitsu. 


\section{INTRODUÇÃO}

Um dos significados do termo “Oss”, segundo a Federação Paulista de Jiu-Jitsu (2015), é a de "perseverar enquanto se é empurrado, ou seja, não desistir jamais, ter determinação, disposição e suportar o mais árduo dos treinamentos, continuar sem desistir, sob qualquer pressão". Essa definição é pertinente quando se verificam as exigências para a prática do esporte e, ainda mais, para atletas que participam de campeonatos do esporte. São muitos os trabalhos que demonstram essas exigências e as decorrências derivadas, tais como o consumo excessivo de suplementos alimentares (PIERI; LOBO 2009) ou do engajamento intenso nos treinamentos e em lutas como forma de aquisição de identidade social (SILVEIRA, 2011; NOVAES, 2012).

A prática de Jiu-jitsu vem crescendo em todo o mundo, ancorado no crescimento das mixed-martial arts, ou MMA (KIM et al., 2008; KIM; ANDREW; GREENWELL, 2009; RUFINO; DARIDO, 2010). Conforme Ribas (2012), a criação do MMA foi uma estratégia da família Gracie, no Brasil, para a difusão do Jiu-jitsu e para demonstrar sua superioridade sobre as demais modalidades de artes marciais. Isso fez com que diversas academias e empresas especializadas em artigos para a prática do esporte surgissem.

Analisando a prática do esporte, em si, como uma forma de consumo, são diversos os fatores que motivam a sua procura. Por um lado, Tavares Júnior, Silva e Drigo (2003), por exemplo, revelaram que $48,35 \%$ de seus entrevistados afirmam praticá-lo como forma de lazer e 32,25\% como forma de obter autoconfiança e defesa pessoal. Esmeraldino e Graça (2014), também, demonstram que 50\% dos praticantes buscaram o esporte por lazer.

Por outro lado, estudos apontam as "dores" advindas da prática do esporte para competição, tais como a necessidade de os atletas racionalizarem e controlarem a dor (THOMAZINI; MORAES; ALMEIDA, 2008), dores físicas e crônicas e lesões, desde brandas a imobilizadoras e graves (PAIVA, 2009) e a utilização de substâncias lesivas ou, mesmo, ilícitas, prejudiciais ao corpo e à mente do atleta, com promessas de atalho para se atingir um desempenho adequado à competição (BITTENCOURT; GUIMARÃES, 2017).

Há aqui, então, uma controvérsia: como serviços que demandam ou conduzem a exigências negativas dos clientes ou que possuem baixo desempenho podem gerar satisfação? Arnould e Price (1993) já haviam demonstrado que, em experiências extraordinárias, que retiram o cliente de seu cotidiano e que o ligam a uma atividade de superação, com forte apelo emocional distorcem as expectativas e conduzem a uma satisfação geral. Dessa forma, o objetivo desse estudo é o de comparar a perspectiva mainstream de análise de satisfação do 
cliente em serviços, baseada na relação expectativa-desempenho, com a perspectiva de marketing de experiências, utilizando-se da prática de jiu-jitsu e da preparação para campeonatos em uma academia em Patos de Minas/MG.

Acredita-se que o estudo possa contribuir para um entendimento maior dos aspectos relacionados à satisfação de clientes em serviços e que auxilie empresas que atuem com processos que os clientes participem e que os considerem negativos, como academias e escolas, possam entender melhor os fatores que fazem com que esses clientes continuem utilizando esses serviços.

\section{ARCABOUÇO TEÓRICO}

A satisfação dos clientes é um tema amplo e muito valorizado pelas empresas que desejam adotar a qualidade de seus produtos e serviços como uma vantagem competitiva (ROSSI, SLONGO, 1998). No campo de comportamento do consumidor, ela é uma das responsáveis por fazer com que os clientes comprem outros produtos/serviços das organizações, sejam fidelizados e influenciem na compra de outros potenciais clientes, como já demonstrado em diversos modelos do processo de decisão de compra, como, por exemplo, o fator experiência em Nicosia (1966), a satisfação e insatisfação como influenciador da busca externa em Blackwell, Kollat e Engel (1968) e a avaliação pós-compra como estímulo em Howard e Sheth (1969).

A satisfação de clientes possui diversas conceituações dependendo da matéria e linha de pensamento utilizados e pode ser entendida desde um contentamento com uma transação específica ou com a acumulação em diversas transações específicas, entendida pelos profissionais de marketing (BOULDING et al., 1993; JOHNSON; ANDERSON; FORNELL, 1995), perpassando uma noção subjetiva de bem-estar, proveniente da psicologia econômica (RAAIJ, 1981), até a visão de expectativa de utilidade econômica aliada à utilidade do consumo pós-compra, advinda da economia (JOHNSON; ANDERSON; FORNELL, 1995).

Assim como a visão racional do comportamento do consumidor é o mainstream atual sobre a matéria (ROSSI; SLONGO, 1998), pode-se dizer que a satisfação de clientes baseada nos estudos sobre qualidade em serviços, com base nos gaps entre expectativa do cliente e os resultados percebidos em relação ao serviço prestado é o mainstream desses estudos (SALOMI; MIGUEL, 2002). Oliver (1980), por exemplo, conceitua a satisfação do cliente como a comparação entre a expectativa de consumo de um produto ou serviço e o resultado alcançado com o consumo. Para esse autor, as expectativas são alvos a serem perseguidos e, quando são ou não são alcançados, geram satisfação ou insatisfação, respectivamente. Já 
Churchill e Suprenant (1982) relacionam a satisfação à comparação entre a recompensa e os custos envolvidos com a compra.

Para Salomi e Miguel (2002), essas definições, posteriormente, culminaram em modelos de análise de qualidade de serviço, sendo os mais utilizados o modelo de gap e o instrumento Servqual, ambos constituídos nos estudos de Parasuraman, Zeithaml e Berry $(1985 ; 1988)$. Nesses estudos, os autores propõem que a satisfação é derivada das diferenças ( $g a p$ ) entre a expectativa e o desempenho sobre 22 variáveis, agrupadas nas dimensões de confiabilidade (capacidade de realizar o serviço prometido), presteza ou receptividade (disposição em auxiliar o cliente), segurança (capacidade de transmitir confiança pela cortesia e pelo conhecimento), empatia (prover atenção individualizada) e aspectos tangíveis (infraestrutura, pessoal, material utilizado).

Contudo, as críticas ao modelo expectativa-desempenho como preditor da satisfação de clientes são muitas. Spreng, MacKenzie e Olshavsky (1996), examinando os determinantes da satisfação do cliente, verificaram que os desejos do consumidor podem reduzir ou suprimir os gaps entre expectativas e percepções de resultados nas variáveis propostas no instrumento Servqual. Outra crítica parte do modelo de necessidade que, segundo Schneider e Bowen (2000), não conseguem explicar reações de satisfação de clientes que estão imbuídos de uma carga emocional mais intensa com o produto ou serviço.

Nessa mesma linha, está o modelo de marketing de experiências que, ao invés de focar nas características de um serviço ou produto como meios para o atendimento das expectativas dos clientes, foca no próprio cliente e em como experiências únicas, individualizadas, e os aspectos subjetivos, envolvem os clientes emocionalmente e os levam à satisfação. Pine II e Gilmore (1998), por exemplo, demonstram como o papel da subjetividade presente no comportamento do consumidor pode gerar um novo tipo de economia. Os autores propõem a economia de experiências em que, por meio do oferecimento de experiências memoráveis, organizações cruzarão a fronteira da economia de serviços, utilizando-os e os produtos relacionados apenas como elementos para vender o que realmente importará: experiências. As experiências, ao contrário de produtos em que o que importa são as características de diferenciação ou de serviços, pelos benefícios, oferecerão sensações inesquecíveis aos "convidados para o show". Assim, o engajamento dos consumidores nestes eventos memoráveis, e não os aspectos tangíveis, fará com que estes percebam os resultados. Também, Holbrook e Hirschman (1982) argumentam que os modelos baseados nos aspectos funcionais e na maximização econômica, com base no processamento de informações está incompleto, devendo contemplar os aspectos subjetivos, numa visão denominada de 
perspectiva experiencial. Assim, os autores apresentam um modelo em que, além da satisfação acarretada pelas experiências de compra, são associadas a ela sensações, imagens, sentimentos, prazeres e outros componentes simbólicos e hedônicos.

Entretanto, o que motivou esse artigo parte de Arnould e Price (1993) em seu estudo sobre experiências extraordinárias, no caso a prática do rafting. Os autores demonstram que a decisão pela aventura de rafting é pouco deliberada ou com pensamentos no alto custo ou tempo despendido. A resposta do porquê da decisão deste tipo está ligada à vontade de realizar algo diferente, ter diversão, mesmo sem os consumidores terem despendido tempo em fazer pesquisas ou possuir expectativas sobre o período anterior à aventura.

Durante a aventura, são elementos importantes a configuração, os guias e outras pessoas no sentido de articular as narrativas da experiência. O guia é importante em construir a expectativa e, posteriormente, as consequências de saída e critérios de avaliação (HOLBROOK; HIRSCHMAN, 1982) de forma a enaltecer a experiência de transformação única que os consumidores obterão. A narrativa de sucesso cria laços temporários profundos e íntimos entre guias e consumidores e demonstra o que realmente é importante na vida. A experiência criada é extraordinária e, apesar de difícil descrição, por causa da carga emocional, fácil de ser lembrada por anos.

Assim, a satisfação, em experiências extraordinárias, está ligada não aos atributos da experiência, em si, mas, sim, ao sucesso da narrativa (ARNOULD; PRICE, 1993). No paradigma tradicional de satisfação os consumidores possuem expectativas que, pela diferença entre o desempenho do produto ou serviço consumido, formará a (in)satisfação. Nas experiências extraordinárias, as expectativas são vagas, pois os consumidores desejam desempenhos emocionais intensos, sem saber quais alternativas os farão produzir. Essas emoções desejadas são subjetivas e derivadas de situações individuais e sociais ocorridas. $\mathrm{O}$ mesmo ocorre com a predição do próprio comportamento esperado para este tipo de experiência, dificultando a formação das expectativas e, consequentemente, da ligação com a satisfação. Outro motivo, é que este tipo de experiência é espontâneo e não ensaiado, características contrárias às rotinas cotidianas e valorizadas pelos consumidores. Isto faz com eles evitem a criação de expectativas sobre a experiência, tornando a busca de informação, com um caráter mais exploratório (HOLBROOK; HIRSCHMAN, 1982).

Da mesma forma, como revelado por Arnould e Price (1993), em experiências extraordinárias, o desempenho não corresponde à satisfação geral. No estudo realizado pelos autores, há diversas situações de maus desempenhos em diversos atributos relacionados a este tipo de experiência, mas há uma satisfação inigualável no final do processo da experiência. 
Mesmo em total nível de momentos negativos durante o processo de experiência, como em praticantes intensos de artes marciais, há relatos de alta satisfação (como o crescimento pessoal, a eficácia e a autenticidade derivados dos ferimentos, desgastes e medo provenientes da prática de artes marciais), como demonstrado neste estudo. Isto demonstra que os critérios de avaliação não são somente funcionais e que as consequências do consumo estão muito ligadas a fatores subjetivos (HOLBROOK; HIRSCHMAN, 1982).

Nesta linha, Andersen e Larsen (2016) argumentam que o processo de formação de um conceito de satisfação é complexo e não se dá, simplesmente, de forma cognitiva-racional, demonstrando a necessidade de outros estudos para uma compreensão mais aprofundada. Para Grimmelikhuijsen e Porumbescu (2017), este processo de julgamento da satisfação pode ser formado a partir de vieses cognitivos inatos, catalisados por aspectos simples dos clientes; sendo, também, influenciadores das expectativas e do desempenho. Para os autores, esta tríade, expectativa-desempenho-satisfação pode não ocorrer nesta ordem, inclusive.

Da mesma forma, estes resultados condizem com os aqueles encontrados por Forero e Gómez (2017), em uma pesquisa envolvendo dezenas de atributos de satisfação na prestação de serviços na área de saúde, eles perceberam contradições na tentativa de extrair conclusões sobre os atributos que geram satisfação e insatisfação, principalmente, em função da dificuldade de se estabelecer o nível de desconfirmação gerada pelo acaso ou pela escala utilizada, em relação ao nível de desconfirmação que revela insatisfação ou satisfação.

Em relação à entrega de experiências extraordinárias, apesar de a literatura sobre serviços fornecer importantes chaves para seu entendimento, como a importância da configuração do serviço, do processo e da relação entre fornecedor e cliente para determinar a satisfação, estas estão ligadas a fatores primordialmente técnicos e funcionais. Assim, fatores negligenciados por esta literatura, como a construção de emoções autênticas e de narrativas promulgadoras de valores, interações e excitações, além da formação complexa de rituais, proporcionam relevante influência sobre a satisfação dos consumidores, não refletindo, necessariamente, o desempenho avaliado dos atributos do serviço.

Também, um importante aspecto no sucesso na entrega de experiências extraordinárias são as relações entre consumidores e fornecedores do serviço, que pode ser desde uma interação mais demorada com um empregado para criar uma relação emocional até uma participação intensa com os diversos "fornecedores" de um serviço, que procuram orquestrar conteúdos emocionais, narrativos e ritualísticos, por meio de habilidades, engajamentos, emoções e sensos dramáticos, a fim de satisfazer seus consumidores (ARNOULD; PRICE, 1993). 
Chiesa et al. (2020), em um estudo sobre aconselhamento de carreiras, demonstrou que a preparação de atletas para campeonatos é um serviço intangível, variável e altamente personalizado, sendo, portanto, difícil para os clientes saber o que esperar dele.

\section{METODOLOGIA}

Este estudo possui uma abordagem qualitativa, ancorada nas literaturas sobre marketing experiencial e sobre satisfação de clientes e nas percepções de praticantes de jiu-jitsu. Inicialmente, foi realizado um levantamento sobre os principais conceitos sobre expectativa, satisfação e desempenho e os fatores que os influenciam. Em seguida, buscou-se a visão da satisfação de clientes na literatura sobre marketing experiencial.

A partir dos conhecimentos captados, optou-se pela investigação em uma academia de jiu-jitsu que estivesse realizando treinamento de alunos para a participação em campeonatos. Conforme recomendações de Dias (2000), de um máximo de 12 pessoas, foram selecionados sete atletas para participarem de um grupo focal na maior academia de Patos de Minas, em número de alunos, constituindo o total de atletas que participariam do campeonato. Os atletas participaram da Copa Leão Dourado de Jiu-Jitsu de Minas Gerais, em Belo Horizonte. A coleta de dados foi realizada no dia 19 de abril de 2019, após o término do campeonato, visando a extrair as experiências dos atletas. Para facilitar a análise, foi gravado e transcrito o áudio da entrevista.

O grupo focal buscou extrair as expectativas e as experiências vividas por esses atletas antes, durante e depois do campeonato. O objetivo foi o de verificar a relação dessas expectativas e experiências com a (in)satisfação durante o processo de treinamento, a (in)satisfação sobre o desempenho dos atletas durante o campeonato e a (in)satisfação geral após o campeonato.

Para a condução do grupo focal, foi elaborado um roteiro de entrevista semiestruturado com perguntas relacionadas ao constructo expectativa-desempenho-satisfação divididas em: i) durante o treinamento, ii) durante o campeonato e iii) após o campeonato.

Após a coleta de dados, esses foram transcritos e analisados por meio da técnica de análise de conteúdo que, segundo Bardin (1991), pode ser utilizada em diversos tipos de discursos, com o objetivo de entender estruturas e modelos subentendidos nas mensagens, codificando-as, classificando-as e categorizando-as. Ao final do trabalho, buscou-se sintetizar os resultados em um quadro-resumo. 


\section{RESULTADOS E DISCUSSÕES}

\subsection{Perfil dos atletas}

Foram entrevistados sete atletas praticantes de jiu-jitsu, todos do sexo masculino, que estão na faixa de 18 a 29 anos, excetuando-se um atleta, com 51 anos. Todos são alunos da academia e pagam, mensalmente, o valor para terem um professor, o ambiente de treinamento e as oportunidades de colocarem à prova seus esforços. Quatro atletas praticam o esporte entre um e dois anos, dois entre cinco e seis anos e um há oito anos. Dos sete atletas, cinco não haviam participado de qualquer campeonato oficial, um havia participado apenas de um e outro atleta participou de três campeonatos oficiais. Entre os dois atletas que já haviam participado de campeonato oficial, um não havia ganhado qualquer premiação, enquanto que o participante de três campeonatos oficiais, havia ganhado medalha de prata, ficando em segundo lugar em um dos campeonatos.

Seus treinamentos regulares são realizados três vezes por semana de duas horas cada e, três meses antes de qualquer campeonato oficial, incluindo o campeonato citado nesse estudo, são realizados treinamentos intensivos diários, de três horas cada, excetuando-se aos domingos. $\mathrm{O}$ treinamento intensivo é um serviço prestado à parte pela academia, com valores diferenciados das aulas regulares de jiu-jitsu.

Cada treinamento é dividido em dois momentos: uma fase de preparação física, em torno de uma hora e uma fase de treinamento de técnicas, em uma ou duas horas. A preparação física contempla atividades para o desenvolvimento de resistência, de força e de flexibilidade que, segundo o professor de jiu-jitsu, são os pilares para o atleta dessa arte marcial. Já o treinamento de técnicas é realizado observando-se os golpes por categoria, por faixa e, também, por campeonato, já que campeonatos diferentes permitem e restringem técnicas diferentes. Nos treinamentos intensivos, os atletas os realizam isolados de outros alunos que, segundo o professor, refletem na concentração e na maximização do tempo do treinamento.

\subsection{Treinamento: incertezas e dor}

Como citado na seção anterior, a fase de treinamento intensivo dos atletas dessa academia começa três meses antes do período de treinamento. Em específico, para a Copa Leão Dourado de Jiu-Jitsu, os treinamentos iniciaram-se no início de fevereiro de 2019. 
Diversos são os aspectos levantados pelos atletas em relação à expectativa, ao desempenho do serviço prestado e à satisfação nessa fase, que serão expostos nessa seção.

É unanimidade entre os entrevistados que, na fase de treinamento, eles elevem seu potencial físico e sua capacidade técnica de executar golpes e de elaborar táticas, tanto de defesa, quanto de ataque. Em relação à capacidade técnica, um dos entrevistados argumenta que "o que esperava, é que todo dia meu físico ficasse melhor, tipo assim, respirar melhor, ter mais força, mais flexibilidade... é isso". Outro entrevistado demonstra que a preocupação com o treinamento transcende a academia dizendo que "a gente já sabia que ia faltar no trabalho e não tava (sic) nem aí. Se o patrão enchesse o saco, fazer o que né (sic)”. Um entrevistado argumenta que, nessa fase, "a gente fica toda hora no Youtube, procurando vídeo, para aprender técnicas, visualizar elas... sabe?", seguido da concordância dos demais.

A expectativa dos serviços prestados pela academia, excetuando-se os veteranos em campeonatos, era incerta. Um dos entrevistados que nunca havia participado de campeonatos diz que "temos o melhor professor da cidade e os aparelhos né (sic). Tipo assim, falta alguns aparelhos, mas tá ( $\mathrm{sic}$ ) bom. Quando paguei para treinar mesmo [treinamento intensivo] pro (sic) Leão Dourado, não sabia o que ia dar”. Outro entrevistado, que já havia participado de campeonatos contra-argumenta, dizendo que "depende muito mais da gente do que do professor, da academia. Mas achava que podia dar mais ajuda. Quando participei a primeira vez, nem pensei nisso [expectativas em relação ao físico e à técnica]”. Outro entrevistado argumenta que "a adrenalina é grande. Parece que só de falar em treinar pra (sic) campeonato, o negócio fica mais sério. A gente só conversa sobre isso". Por fim, um dos entrevistados disse que "quando meu sensei [mestre, professor] me chamou [para participar do campeonato], nem acreditei. Aceitei de boa. Paguei e fui. Tem que confiar no cara né (sic) [referindo-se ao desempenho do professor em outro campeonato, o qual ganhou]. O problema foi depois".

Esses depoimentos parecem concordar com a dissociação do pensamento racional na busca por serviços proposta por Arnould e Price (1993) e as expectativas. Mesmo com aspectos negativos sendo apontados em relação aos serviços prestados pela academia para a participação no campeonato, parece haver uma dissonância entre o que a academia oferece e o que se deseja. Apesar de o estudo dos autores ter como plano de investigação uma experiência extraordinária, os autores revelaram que a decisão pela aquisição de serviços motivados pelas emoções é pouco deliberada e não associada a avaliações de custo ou tempo, estando mais ligada à realização de algo fora do ordinário, do cotidiano. Assim, as expectativas são vagas, pois os alunos-clientes desejam desempenhos emocionais intensos com o campeonato, sem 
saber, com clareza, quais alternativas os farão produzir. Neste caso, o sensei (professor, mestre) possuiu um papel fundamental na aquisição do serviço, seja por a) sua narrativa sobre o campeonato, seja por b) ser um referencial para os alunos.

Em relação ao desempenho, durante o processo de treinamento intensivo, muitos dos alunos se frustraram com os serviços prestados pela academia. Um dos entrevistados disse que "podia ter sido melhor. Tinha muita enrolação no começo do treino. Muita conversinha, sabe? Tinha que indicar os aparelhos certos". Outro entrevistado argumentou que "punha muita carga na gente (sic), parecendo que tinha que conseguir tudo num dia só". Sobre o mesmo assunto, um entrevistado disse que "chegava em casa moído. No outro dia, eu ficava com o corpo todo doído". Além disso, um entrevistado apontou que "o horário era problemático" e que "tinha ( ic ) aparelhos estragados na hora da musculação".

Contudo, quando eram perguntados sobre a satisfação no final do treino, os entrevistados, com poucas divergências, pareciam concordar em existir um contentamento por ter passado mais uma fase para atingir o objetivo final. Um desses entrevistados disse a seguinte frase: "apesar desses probleminhas, a gente sabe que o dia tá (sic) chegando. Não tem que ficar reclamando não. Tem que preparar. Depende muito da gente. Eu, por exemplo, quando passa o treino, acho bom, porque sei que fico melhor para a copa (campeonato)".

Verifica-se, a partir dos relatos, que há uma incoerência no modelo expectativadesempenho-satisfação. Parece haver uma incerteza em relação às expectativas, mas, mesmo assim, levados pela emoção, os atletas se engajam nos treinamentos oferecidos pela academia. Durante o processo, devido à intensidade do treinamento e a outros fatores relacionados à infraestrutura da academia, os atletas demonstraram haver um baixo desempenho do serviço prestado. Contudo, há uma satisfação ao término de cada treino e que o seu nível parece se intensificar à medida que vai se treinando. Neste caso, verifica-se uma inconsistência na relação entre o desempenho percebido e a satisfação durante esse processo, o que leva a crer que expectativas incertas e motivadores interferem na relação desempenho-satisfação.

Estes achados não destoam daqueles encontrados por Grimmelikhuijsen e Porumbescu (2017), pois, para eles, os julgamentos de satisfação podem ser moldados por vieses cognitivos inatos, desencadeados por questões simples que envolvem os julgamentos dos clientes; bem como, vários aspectos influenciam as expectativas, o desempenho e a satisfação, os quais, não necessariamente, precisam ocorrer nesta ordem cronológica. Ademais, para Andersen e Larsen (2016) a formação de um julgamento de satisfação não é um simples processo cognitivo-racional. Portanto, mais pesquisas sobre como os processos cognitivos e vieses, que afetam a satisfação dos clientes, podem ajudar a entender melhor esse fenômeno. 


\subsection{O campeonato e pós-campeonato: emoções à flor da pele}

Um dia antes do campeonato os atletas se aprontaram para a viagem para Belo Horizonte, o que permitiu que fossem tecendo comentários e apontando suas expectativas durante o trajeto. Nos depoimentos, é possível perceber a ansiedade dos atletas em relação ao campeonato. No grupo focal, um deles argumenta que, na viagem, dizia que "devia ter treinado mais as quedas (golpes que derrubam o oponente)". Outro lembrou que ficava pensando que "não ganhou o peso pra chegar no limite (o limite de peso da categoria dele)" e que "isso faz diferença [entre ganhar e perder]". Quando perguntados sobre as emoções que sentiram, os atletas demonstraram que estavam, conforme fala de um deles, com as emoções “à flor da pele" e que "vai ser difícil dormir aqui (na viagem)".

Argumentados sobre o que pensavam sobre o treinamento oferecido pela academia no momento da viagem e durante o campeonato, a maioria deles demonstrou-se incerta sobre sua preparação e que "só dava pra (sic) saber quando chegasse a luta", disse um deles. Outro argumentou que ele não foi orientado sobre lesões e respectivos procedimentos e "se acontecer, não sei se vai ter médico"; afirmativa que teve concordância dos demais. Contudo, todos pareciam estar determinados a enfrentar esses medos: "tem que ser guerreiro", disse um; outro bradou que "isso não é pra (sic) qualquer um não. Tem que ter coragem". Essas frases demonstram que é a busca por emoções a impulsionadora que supera as incertezas derivadas dessa experiência.

Eles foram questionados sobre o local de estadia e a alimentação, que usufruiriam. Também, pareciam desconhecer, em muitos aspectos o que seria oferecido. Um deles disse “eu, por exemplo, não tava (sic) nem aí com isso não", concordando os demais. Outro disse que "se tivesse cama e comida tava (sic) valendo. O que importa é a adrenalina". Mais uma vez, as emoções parecem suprimir a racionalidade e tornar as expectativas incertas.

Em relação ao desempenho do serviço, quando questionados sobre as instalações, um dos atletas disse que "dava pro ( sic) galho, mas podia ter sido melhorzinho (o quarto). Ficar quatro [homens] dentro de um cubículo foi barra [ruim]". Outro entrevistado complementa dizendo que "realmente era pequeno. Não dava nem para treinar as técnicas". Sobre o café da manhã do hotel, um atleta disse que "ainda bem que levei meus shakes (bebidas proteicas). $\mathrm{O}$ café não dava nem pro (sic) gasto (referindo-se à necessidade de uma alimentação mais adequada para a luta)".

Após o primeiro dia, os atletas conduziram-se às dependências do local da luta. Ao se prepararem para a luta, todos os entrevistados foram unânimes em descrever a ansiedade e a 
emoção envolvidas nesse momento. "O coração da gente vai a mill", descreveu um. "Só de ver aquele tanto de gente lá fora pra (sic) ver a gente lutar, já fico ansioso", apontou outro. No momento das chamadas para a luta, um dos entrevistados disse: "quando chamou o meu nome, meu coração tava (sic) pulando pra (sic) garganta". Alguns entrevistados (três) concordaram que, durante algumas lutas, a emoção os dominou e que isso pode ter influenciado em sua derrota. Os outros se disseram controlados e que os resultados refletiram as diferenças de técnicas e de treinamentos entre os atletas.

Os resultados finais foram os seguintes: um atleta foi campeão de sua categoria (adulto, peso pluma), um vice-campeão (adulto, pesado), três em terceiro lugar (um máster, meio pesado, dois adultos, sendo um peso pena e outro médio), outro apenas com participação (adulto, peso leve) e outro desclassificado por WO (não comparecimento), devido a uma distensão muscular. O campeão e o vice-campeão argumentaram que a vitória foi associada, em parte, ao treinamento intensivo, mas que, em maior parte, relaciona-se ao seu próprio esforço, dizendo que "a gente sofre (referindo-se ao treinamento), mas tem o resultado". O que não conseguiu obter qualquer premiação (classificado como participante), além de reforçar a necessidade de ter que treinar mais, argumentou que "agora não paro nunca mais. A sensação é muito boa, mesmo com as dificuldades (do treinamento e dos problemas apontados anteriormente)".

Assim, percebe-se pelos depoimentos que, apesar das dificuldades relacionadas ao treinamento e a alguns aspectos negativos dos serviços prestados pela academia, a satisfação geral, da maioria dos atletas, é relativamente alta, gerada pelas fortes emoções provocadas pelo o ambiente e pela luta em si, no dia do campeonato. Mais uma vez, demonstra que as emoções exercem um papel fundamental na dissociação da relação expectativa-resultado, como geradora de (in)satisfação.

Estes resultados corroboram aqueles encontrados tanto por Grimmelikhuijsen e Porumbescu (2017), quanto por Forero e Gómez (2017), cujos estudos empíricos demonstraram dissonância da satisfação com relação à diferença expectativa-desempenho.

\subsection{Resultados gerais}

A Figura 1 apresenta os resultados gerais da pesquisa. 
Figura 1: Resumo dos resultados

\begin{tabular}{|c|c|c|}
\hline Fases & Treinamento & Campeonato e pós-campeonato \\
\hline Expectativa & $\begin{array}{l}\text { Incerteza em relação a diversos } \\
\text { aspectos tangíveis e intangíveis do } \\
\text { serviço da academia: } \\
\text { - } \text { aparelhos utilizados, } \\
\text { - treinamento e } \\
\text { - resultados }\end{array}$ & $\begin{array}{l}\text { - Incerteza em relação ao esperado para } \\
\text { a luta no campeonato. } \\
\text { - Incerteza em relação à integridade } \\
\text { física. }\end{array}$ \\
\hline Desempenho & $\begin{array}{l}\text { Baixo desempenho em alguns } \\
\text { aspectos do serviço da academia: } \\
\text { - } \text { aparelhos utilizados, } \\
\text { - } \quad \text { horário de treinamento e } \\
\text { - } \quad \text { altas exigências físicas }\end{array}$ & $\begin{array}{l}\text { - O grupo demonstrou várias falhas do } \\
\text { serviço para auxiliar no atingimento } \\
\text { do objetivo de passar pelo treinamento } \\
\text { e de ganhar o campeonato. }\end{array}$ \\
\hline (In)satisfação & $\begin{array}{l}\text { Mescla de satisfação e insatisfação a } \\
\text { cada treinamento: } \\
\text { - } \quad \text { satisfação gradual ao perceber a } \\
\text { evolução física e técnica e } \\
\text { - } \quad \text { insatisfação por não alcançar } \\
\text { melhores resultados físicos e } \\
\text { técnicos ao término do ciclo de } \\
\text { treinamentos }\end{array}$ & $\begin{array}{l}\text { - Satisfação alta, com diversos } \\
\text { componentes do grupo, demonstrando } \\
\text { contentamento em, simplesmente, } \\
\text { estar participando do campeonato, } \\
\text { carregada de forte emoção. } \\
\text { - Satisfação, relativamente, mais alta do } \\
\text { que as mencionadas em outras fases, } \\
\text { correlacionado aspectos de superação } \\
\text { nos treinamentos e de forte emoção em } \\
\text { participar do campeonato como } \\
\text { catalisadores dessa satisfação. }\end{array}$ \\
\hline Observação & $\begin{array}{l}\text { Percebe-se certa dissociação do } \\
\text { modelo expectativa-desempenho- } \\
\text { satisfação, principalmente no que } \\
\text { tange à relação desempenho- } \\
\text { satisfação. }\end{array}$ & $\begin{array}{l}\text { Neste caso, há incertezas sobre a } \\
\text { expectativa e, novamente, parece haver } \\
\text { dissonância na relação desempenho- } \\
\text { satisfação. }\end{array}$ \\
\hline
\end{tabular}

Fonte: elaborado pelos autores a partir dos resultados da pesquisa (2019).

Observa-se que, de forma geral, há uma dissociação na relação expectativadesempenho-satisfação, demonstrando que há uma indefinição das expectativas sobre o treinamento e sobre o campeonato, além de demonstrar que a relação entre o desempenho obtido pelos serviços prestados pela academia e a satisfação em cada fase foi divergente em 
relação ao modelo de necessidades, o qual propõe que, quando o resultado fica abaixo das expectativas, o cliente fica insatisfeito (SCHNEIDER; BOWEN, 2000). É importante destacar que Chiesa et al. (2020) apontaram que os serviços relacionados à preparação de atletas constituem-se como altamente intangíveis, variáveis e personalizados, prejudicando a expectativa dos clientes. A Figura 2 demonstra uma representação dessa dissociação entre a satisfação esperada pela perspectiva mainstream (expectativa-desempenho-satisfação) e a satisfação observada.

Figura 2: Comparação da relação expectativa-desempenho e a satisfação entre o mainstream (esperado) teórico e os resultados observados

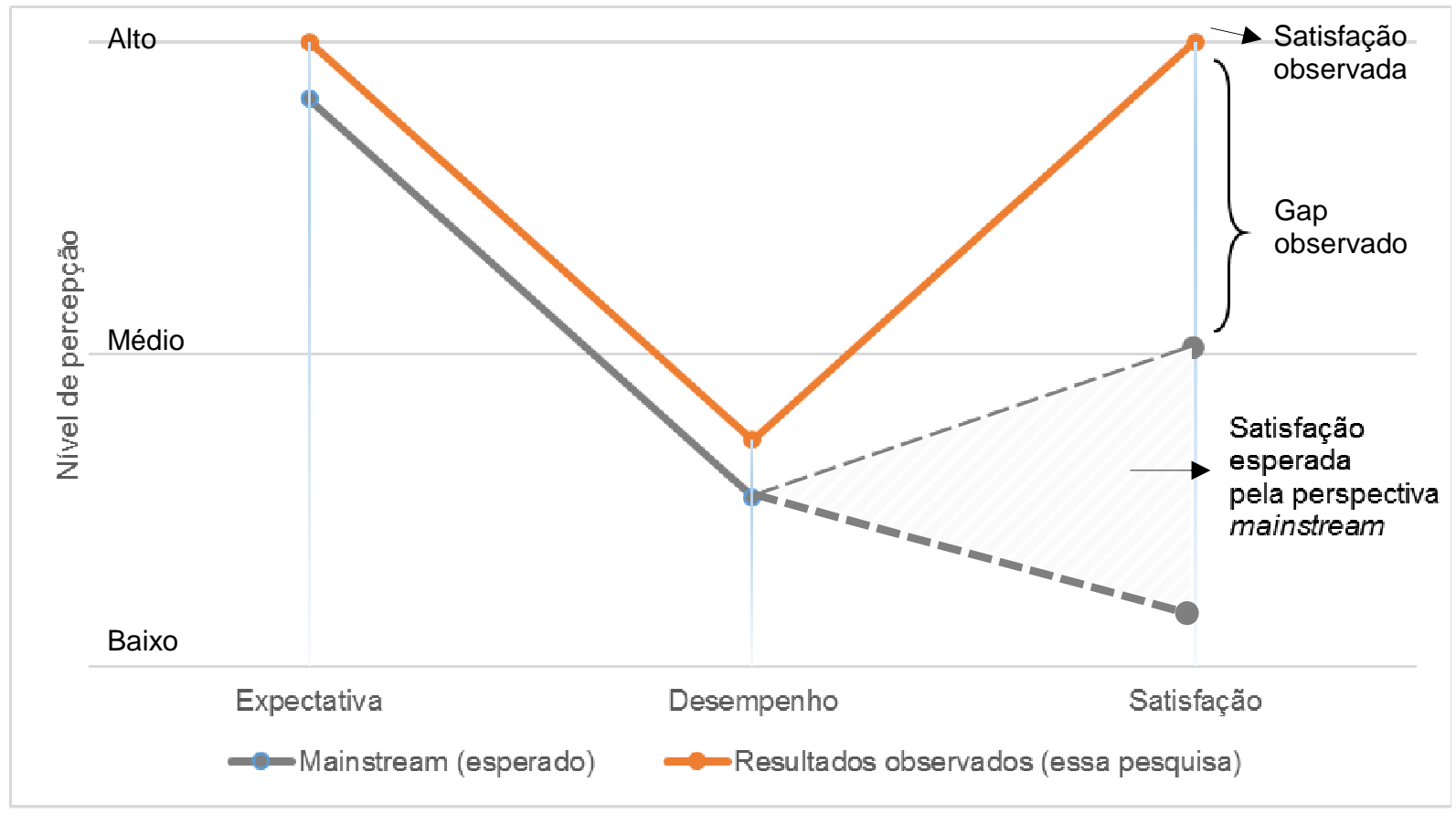

Nota.: área rachurada representa o resultado de satisfação esperado, segundo o paradigma mainstream da relação expectativa-desempenho-satisfação.

Fonte: elaborado pelos autores a partir da análise dos resultados encontrados (2019).

\section{CONSIDERAÇÕES FINAIS}

O objetivo do estudo foi o de analisar as relações entre as dimensões de expectativaresultados-satisfação na prestação de serviços de preparação para campeonatos de uma academia de jiu-jitsu, comparando essas relações aos modelos de necessidade e de experiências.

De forma geral, parece haver uma dissociação, nesse caso, no modelo de necessidade, haja vista que as expectativas em relação aos diversos aspectos desse serviço eram incertas. 
Nesse caso, não há formação de um corpo concreto comparativo, que permita relacionar o resultado à sensação de satisfação ou insatisfação. Nesse caso, durante o treinamento, houve uma dissociação entre o resultado baixo e a satisfação mediana e, gradativamente, aumentando. Essa dissonância, como já abordado por Arnould e Price (1993), parece estar fortemente ligada às emoções desejadas, fazendo com que os atletas relevem e superem aspectos negativos do serviço.

Também, durante o campeonato, as expectativas eram incertas e, novamente, os baixos resultados alcançados com alguns aspectos do serviço destoaram da satisfação alcançada com a participação. Outra vez, agora de forma mais intensa, as fortes emoções envolvidas durante as lutas, fizeram com que os atletas suprimissem percepções negativas do serviço em prol da satisfação alcançada com a participação no campeonato.

Mais uma vez, a pesquisa demonstra que há uma dissonância entre a relação a) resultados alcançados com o serviço e b) satisfação geral. Após os atletas serem convidados a refletirem sobre essas variáveis, confirmaram que houve vários erros por parte deles e do treinamento, mas que, de forma geral, estavam muito satisfeitos com tudo e que continuarão a participar dos campeonatos utilizando-se do treinamento intensivo da mesma academia, mesmo depois das insatisfações com o caminho trilhado para participar do campeonato.

Assim, para esse tipo de serviço, o qual envolve clientes que desejem evoluir e participar de competições, parece-se adequar mais ao modelo de experiências de uma forma um tanto controversa: a superação de desafios e o forte apelo emocional, aliados às narrativas do professor parecem suplantar as adversidades encontradas durante todo o processo.

Para aplicações gerenciais, abre-se a perspectiva de uma análise diferenciada baseada na verificação de objetivos dos clientes e nos meios que conduzem à superação das adversidades para o atingimento desses objetivos em serviços que possuem, em suas atividades-meio, aspectos negativos, tais como academias e escolas. Contudo, os resultados encontrados de que há uma desvinculação entre expectativas, desempenhos e satisfação geral sobre determinados serviços devem ser analisados com cautela, pois, por mais que os consumidores consigam demonstrar satisfação final em serviços com processos intermediários de médio e baixo desempenhos, pode haver desistência do serviço por parte do consumidor ao avaliar o desempenho de aspectos do serviço no meio do processo, demonstrando que a relação expectativa-desempenho-satisfação não deve ser ignorada.

Um limitador dessa pesquisa que merece ser destacado e que potencializa outros estudos está ligado ao fato de que o grupo focal foi conduzido somente ao final do campeonato, realizando, então, do artifício de resgate da memória dos atletas sobre as diversas fases de 
antes, durante e depois do treinamento e do campeonato, sendo, esse último, menos influenciado pelo lapso temporal. Dessa forma, sugere-se que uma imersão seja conduzida sobre as diversas fases do serviço e do campeonato, em si, para que sejam extraídas informações mais precisas sobre as dimensões de expectativa, de resultados e de satisfação.

Além disso, abre-se caminho para um estudo mais amplo, envolvendo mais casos e abordando, mais profundamente, quais os aspectos emocionais e incertezas influenciam a dissonância encontrada, podendo convergir em um instrumento de pesquisa quantitativo, que permita uma generalização da pesquisa e possa demonstrar a dissonância nas relações expectativa-resultado-satisfação.

\section{REFERÊNCIAS}

ANDERSEN, S. C.; LARSEN, M. H. Cognitive Biases in Performance Evaluations. Journal of Public Administration Research and Theory, v. 26, n. 4, pp. 647-62, 2016. Disponível em: <http://dx.doi.org/10.1093/jopart/muv036>.

ARNOULD, E. J.; PRICE, L. L. River magic: extraordinary and the extended service encounter. Journal of Consumer Research, v. 20, n. 1, pp. 24-45, Jun. 1993. Disponível em: $<$ https://doi.org/10.1086/209331>.

BARDIN F. Análise de conteúdo. Lisboa: Edições 70, 1991.

BITTENCOURT, J. B. M.; GUIMARÃES, F. C. Dentro e fora do octógono: corpo, consumo e êxtase nas tramas do MMA. Revista de Ciências Sociais Política \& Trabalho, v. 34, n. 47, p. 57-74, jun./dez. 2017. Disponível em: <https://doi.org/10.22478/ufpb.15175901.2017v1n47.36660>.

BLACKWELL, R. D.; KOLLAT, D.; ENGEL, J. F. Consumer behavior. New York: Holt, Rinehard, and Winston, 1968.

BOULDING, W.; KALRA, A.; STAELIN, R.; ZEITHAML, V. A. A dynamic process model of service quality: from expectations to behavioral intentions. Journal of Marketing Research, v. 30, n. 1, pp. 7-27, Feb. 1993.

CHIESA, R.; PETRUZZIELLO, G.; MARIANI, M. G.; GUGLIELMI, D. Expectations of career counseling and their effect on client satisfaction. The Career Development Quarterly, v. 68, n. 3, pp. 254-267, 2020. Disponível em: $<$ https://doi.org/10.1002/cdq.12235>.

CHURCHILL JR., G. A.; SURPRENANT, C. An investigation into the determinants of customer satisfaction. Journal of Marketing Research, v. 19, n. 4, pp. 491-504, Nov. 1982. Disponível em: <https://doi.org/10.2307/3151722>.

DIAS, C. A. Grupo focal: técnica de coleta de dados em pesquisas qualitativas. Informação \& Sociedade: Estudos, v. 10, n. 2, p. 1-12, 2000. Disponível em: $<$ https://periodicos.ufpb.br/ojs2/index.php/ies/article/view/330>. 
ESMERALDINO, H. B., GRAÇA, R. L. A contribuição da mídia na adesão e aderência à prática de lutas esportivas e artes marciais. EFDeportes, v. 18, n. 188, Ene 2014. Disponível em: <http://www.efdeportes.com/efd188/a-midia-na-aderencia-a-lutas-esportivas.htm>. Acesso em: 10 jul. 2021.

FEDERAÇÃO Paulista de Jiu-Jitsu. Definição de Oss. FPJJ Competidor 6 jan 2015. Disponível em: <http://fpjjcompetidor.com.br/definicao-de-oss/>. Acesso em: 10 jul 2021. FORERO, D. E.; GÓMEZ, A. Comparison of measurement models based on expectations and perceived performance for the satisfaction study in health services. Suma Psicológica, v. 24, n. 2, pp. 87-96, 2017. Disponível em: <http://dx.doi.org/10.1016/j.sumpsi.2017.06.002〉.

GRIMMELIKHUIJSEN, S.; PORUMBESCU, G. A. Reconsidering the expectancy disconfirmation model: three experimental replications. Public Management Review, v. 19, n. 9, pp. 1272-92, Feb. 2017. Disponível em: <http://dx.doi.org/10.1080/14719037.2017.1282000>.

HOLBROOK, M. B.; HIRSCHMAN, E. C. The experiential aspects of consumption: consumer fantasies, feelings, and fun. Journal of Consumer Research, v. 9, n. 2, pp. 132-40, Sep. 1982. Disponível em: <https://doi.org/10.1086/208906>.

HOWARD, J. A.; SHETH, J. N. The theory of buyer behavior. Columbia: John Willey \& Sons, 1969.

JOHNSON, M. D.; ANDERSON, E. W.; FORNELL, C. Rational and adaptive performance expectations in a customer satisfaction framework. Journal of Consumer Research, v. 21, n. 1, pp. 695-707, Mar. 1995. Disponível em: 〈https://doi.org/10.1086/209428>.

KIM, S. M.; ANDREW, D. P. S.; GREENWELL, T. C. An analysis of spectator motives and media consumption behaviour in an individual combat sport: cross-national differences between American and South Korean Mixed Martial Arts fans. International Journal Sports Marketing Sponsorship, v. 10, n. 2, pp. 157-70, Jan 2009. Disponível em: <http://dx.doi.org/10.1108/IJSMS-10-02-2009-B006>.

KIM, S. M.; GREENWELL, C.; ANDREW, D. P. S., LEE, J.; MAHONY, D. F. An analysis of spectator motives in an individual combat sport: a study of mixed martial arts fans. Sport Marketing Quarterly, v. 17, n. 2, pp. 109-19, June 2008. Disponível em: $<$ https://fitpublishing.com/content/analysis-spectator-motives-individual-combat-sport-studymixed-martial-arts-fans-pp-109-119>.

NICOSIA, F. Consumer decision processes. Englewood Cliffs: Prentice Hall, 1966.

NOVAES, J. de V. Bateu, levou! O que dizem os lutadores de MMA. Polêm!ca, v. 11, n 4, p. 568-80, out./dez. 2012. Disponível em: http://dx.doi.org/10.12957/polemica.2012.4325

OLIVER, R. L. A cognitive model of the antecedents and consequences of satisfaction decisions. Journal of Marketing Research, v. 17, n. 1, pp. 460-69, Nov. 1980. Disponível em: <https://doi.org/10.1177\%2F002224378001700405>. 
PAIVA, L. Pronto pra Guerra: preparação física específica para luta \& superação. Manaus: OMP, 2009.

PARASURAMAN, A.; ZEITHAML, V. A.; BERRY, L. L. A conceptual model of services quality and its implication for future research. Journal of Marketing, v. 49, n. 1, pp. 41-50, Fall 1985. Disponível em: 〈http://dx.doi.org/10.2307/1251430>.

PARASURAMAN, A.; ZEITHAML, V. A.; BERRY, L. L. Servqual: A multiple-item scale for measuring consumer perceptions of service quality. Journal of Retailing, v. 64, n. 1, pp. 12-40, Spring $1988 . \quad$ Disponível em: https://www.researchgate.net/publication/225083802_SERVQUAL_A_multiple_Item_Scale_ for_measuring_consumer_perceptions_of_service_quality

PIERI, B. L. S.; LOBO, A. S. Consumo de suplementos alimentares por praticantes de jiujitsu no município de Criciúma (SC). CONGRESSO NACIONAL DA SOCIEDADE BRASILEIRA DE ALIMENTAÇÃO E NUTRIÇÃO, 10., set 2009. Anais... São Paulo: SBAN, 2009. v. 34 (supl.), p. 111. Disponível em: http://www.sban.org.br/uploads/Revista20200525082606.pdf

PINE II, B. J.; GILMORE, J. H. Welcome to the experience economy. Harvard Business Review, pp. 97-105, Jul./Aug. 1998. Disponível em: <https://hbr.org/1998/07/welcome-tothe-experience-economy>.

RAAIJ, W. F. van. Economic psychology. Journal of Economic Psychology, v. 1, n. 1, pp. 1-24, Mar. 1981. Disponível em: 〈https://doi.org/10.1016/0167-4870(81)90002-7>.

RIBAS D. MMA: origem, evolução, regras e tudo sobre a modalidade [artigo na internet]. News MMA, fev. 2012. Disponível em: <https://newsmma.wordpress.com/2012/01/04/comotudo-comecou-uma-historica-rica-do-mma-desde-o-seu-berco-o-brasil >. Acesso em: 10 jul. 2021.

ROSSI, C. A. B.; SLONGO, L. A. Pesquisa de satisfação de clientes: o estado-da-arte e proposição de um método brasileiro. Revista de Administração Contemporânea, v. 2, n. 1, p. 101-25, jan./abr. 1998. Disponível em: <https://doi.org/10.1590/S141565551998000100007>.

RUFINO, L. G. B., DARIDO, S. C. O jiu jitsu brasileiro na visão dos não praticantes. Coleção Pesquisa em Educação Física, v. 9, n. 2, p. 181-7, 2010. Disponível em: $<$ https://fontouraeditora.com.br/periodico/home/viewArticle/603>.

SALOMI, G. G. E.; MIGUEL, P. A. C. Aplicação de modelos de avaliação da qualidade em serviços para mensuração da satisfação de clientes internos em uma empresa do setor industrial. ENCONTRO NACIONAL DE ENGENHARIA DE PRODUÇÃO, 22., out. 2002. Anais... $\quad$ Curitiba: $\quad$ ABEPRO, $2002 . \quad$ Disponível <http://www.abepro.org.br/biblioteca/ENEGEP2002_TR21_0205.pdf>.

SCHNEIDER, B.; BOWEN, D. E. O modelo das necessidades. HSM Management, Rio de Janeiro, v. 4, n. 23, pp. 65-72, nov./dez. 2000. 
SILVEIRA, I. C. A luta por uma identidade: uma etnografia sobre a subcultura de consumo de MMA. Rio de Janeiro. Dissertação [de Mestrado em Administração Pública e de Empresas] - Fundação Getúlio Vargas, 2011. Disponível em: <https://silo.tips/download/aluta-por-uma-identidade-uma-etnografia-sobre-a-subcultura-de-consumo-de-mma .

SPRENG, R. A.; MACKENZIE, S. B.; OLSHAVSKY, R. W. A reexamination of the determinants of consumer satisfaction. Journal of Marketing, v. 60, n. 3, pp. 15-32, Jul. 1996. Disponível em: <https://doi.org/10.2307/1251839>.

TAVARES JR., A. C.; SILVA, L. H.; DRIGO, A. J. Os motivos da adesão da prática do jiu jitsu na cidade de Rio Claro. Motriz, São Paulo, v. 9, n. 1 (supl.), p. 181-8, 2003.

THOMAZINI, S. O.; MORAES, C. E. A.; ALMEIDA, F. Q. Controle de si, dor e representação feminina entre lutadores(as) de Mixed Martial Arts. Pensar a Prática, v. 11, n. 3, p. 281-90, set./dez. 2008. Disponível em: <https://doi.org/10.5216/rpp.v11i3.4992〉.

\section{Como Referenciar este Artigo, conforme ABNT:}

FERNANDES, R. B; COSTA FILHO, C. G; CAIXETA, R. P; REZENDE, D. C. OSS: Uma Investigação Sobre a Dissonância Entre o Mainstream Expectativa-Desempenho e a Satisfação entre Praticantes de Jiu-Jitsu À Luz do Marketing Experiencial. Rev. FSA, Teresina, v. 19, n. 2, art. 1, p. 322, fev. 2022.

\begin{tabular}{|l|c|c|c|c|}
\hline \multicolumn{1}{|c|}{ Contribuição dos Autores } & $\begin{array}{c}\text { R. B. } \\
\text { Fernandes }\end{array}$ & $\begin{array}{c}\text { C. G. Costa } \\
\text { Filho }\end{array}$ & $\begin{array}{c}\text { R. P. } \\
\text { Caixeta }\end{array}$ & $\begin{array}{c}\text { D. C. } \\
\text { Rezende }\end{array}$ \\
\hline 1) concepção e planejamento. & $\mathrm{X}$ & & $\mathrm{X}$ \\
\hline 2) análise e interpretação dos dados. & $\mathrm{X}$ & $\mathrm{X}$ & $\mathrm{X}$ & \\
\hline 3) elaboração do rascunho ou na revisão crítica do conteúdo. & $\mathrm{X}$ & $\mathrm{X}$ & & $\mathrm{X}$ \\
\hline 4) participação na aprovação da versão final do manuscrito. & $\mathrm{X}$ & $\mathrm{X}$ & $\mathrm{X}$ & \\
\hline
\end{tabular}

